\title{
Degeneração macular relacionada à idade: considerações histopatológicas
}

\author{
Age-related macular degeneration: \\ histopathological considerations
}

Joaquim Marinho de Queiroz1, Joaquim Marinho de Queiroz Junior², Fernando José Carvalho de Queiroz ${ }^{3}$

\section{$\underline{\text { RESUMO }}$}

A degeneração macular relacionada à idade acomete o indivíduo idoso, é de evolução crônica e causa cegueira legal. Clinicamente se apresenta sob duas formas: atrófica ou seca e a exsudativa ou úmida. O quadro histopatológico da forma atrófica é predominante a esclerose da córiocapilar com obliteração parcial ou total do seu lúmen, atrofia do epitélio pigmentar e drusas duras. A forma úmida é caracterizada pela proliferação de neovasos, exsudação sero-hemorrágica, drusas moles e nas fases avançadas da doença, presença de cicatriz disciforme sub-retiniana, na área macular. Fatores angiogênicos têm sido responsabilizados como determinantes do processo neovascular o que levou ao uso de drogas antiangiogênicas no tratamento atual desta patologia.

Descritores: Degeneração macular/patologia; Envelhecimento/fisiologia; Acuidade visual/fisiologia

\footnotetext{
${ }^{1}$ Livre-docente pela Faculdade de Medicina da Universidade Federal de Minas Gerais - UFMG - Belo Horizonte (MG), Brasil; ${ }^{2}$ Mestre em Oftalmologia pela Universidade Federal de São Paulo - UNIFESP - São Paulo (SP), Brasil;

${ }^{3}$ Oftalmologista da Clínica Queiroz - Belém (PA), Brasil.

Instituição: Clínica Queiroz Oftalmologia

Recebido para publicação em: 7/6/2010 - Aceito para publicação em 20/11/2010
} 


\section{INTRODUÇÃO}

A mácula lútea, zona oval, amarelada, localiza da na retina posterior no lado temporal, tem aproximadamente $1.5 \mathrm{~mm}$ de diâmetro; é onde a acuidade visual apresenta maior nitidez. A mácula transmite ao cérebro $90 \%$ da informação visual.

No centro da mácula há uma depressão - a fóvea - e, no assoalho dela, encontramos a foveóla (Figura 1). Na fóvea a retina está reduzida às células fotorreceptoras, os cones e o citoplasma das células de Müller. Na região parafoveal a mácula é espessada por camadas de células ganglionares e de células da camada nuclear interna.

Os cones são responsáveis pela visão da forma, das cores e da visão estereoscópica. A fóvea é avascular, sua nutrição é através da córiocapilar da coróide; são capilares de lúmen alargado e as células endoteliais na sua porção interna são fenestradas .

A córiocapilar da coróide (CCC), a membrana de Bruch (MB) e as células do epitélio pigmentado da retina (EPR) formam em conjunto a barreira hematorretiniana que regula as trocas metabólicas locais (Figura 2).

A córiocapilar coroidiana tem origem nas artérias da camada média da coróide e se continua nos capilares, vênulas, desaguando nas veias vorticosas.

Na região da fóvea os cones são estreitos, intensamente agrupados, o que possibilita detectar a luz de faixas estreitas de comprimento de ondas, importante para a visão das cores.

A cor da mácula é amarelada devido à presença da xantofila, um caroteno que se acumula no pericário do neurônio bipolar e nas células ganglionares desta região. A coróide na área macular é mais espessa e com vasos sanguíneos alargados.

A mácula pode ser afetada seletivamente por processos: inflamatórios, distróficos e degenerativos.

Trataremos nesta exposição da degeneração da mácula relacionada à idade (DMRI), enfatizando a sua histopatologia.

Com o envelhecimento da população um número maior de casos de DMRI está sendo diagnosticado. No Brasil, segundo pesquisa nacional divulgada pelo IBGE, a população idosa continua crescendo e o número de pessoas com idade igual ou superior a 60 anos em 2008, alcançou 21 milhões de brasileiros, representando $11.1 \%$ da população total. Na França, a DMRI atinge mais de 1 milhão de pessoas e é responsável por mais de 3.000 novos casos de cegueira legal, por ano ${ }^{(1,3)}$.

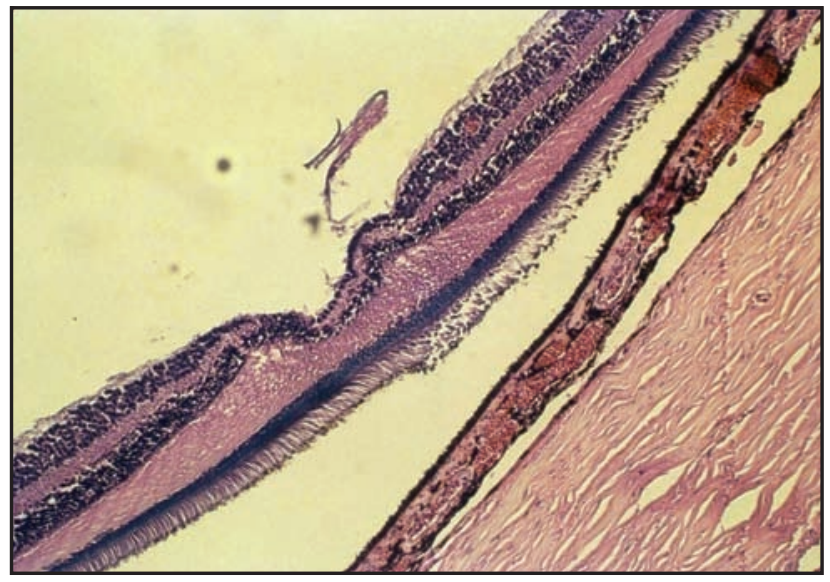

Figura 1. Histologia normal mácula-fóvea, 40x col. HE

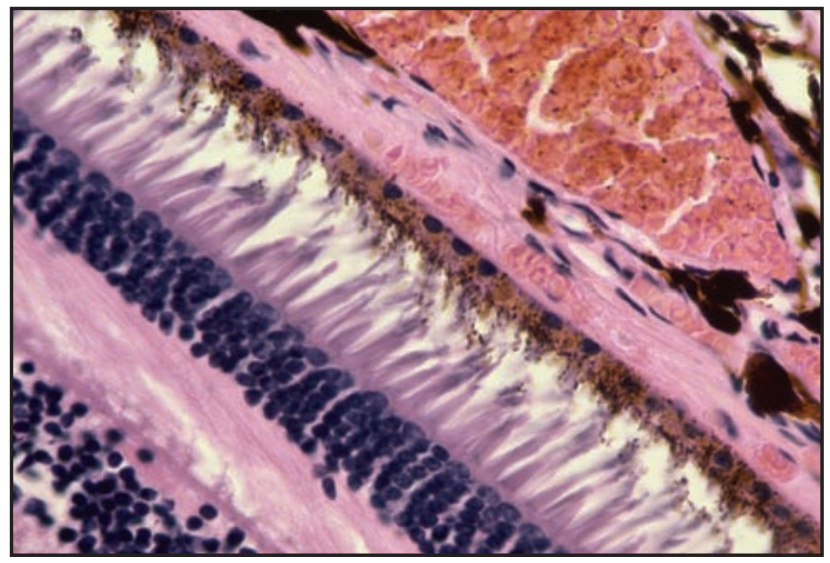

Figura 2: Complexo córiocapilar coróide (CCC), membrana de Bruch (MB), epitélio pigmentado da retina (EPR)

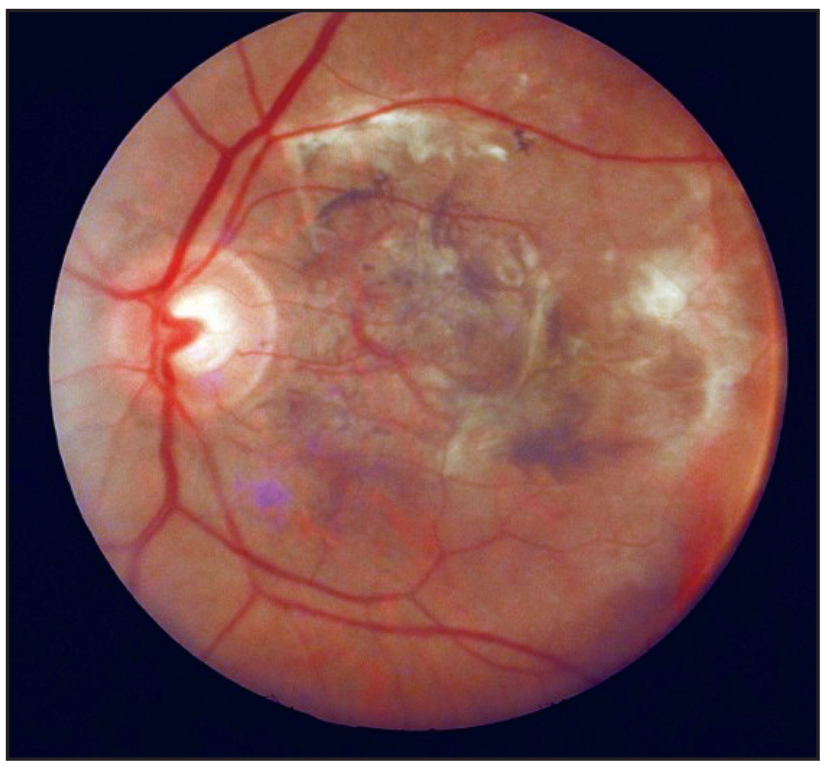

Figura 3: Retinografia simples: DMRI forma atrófica 

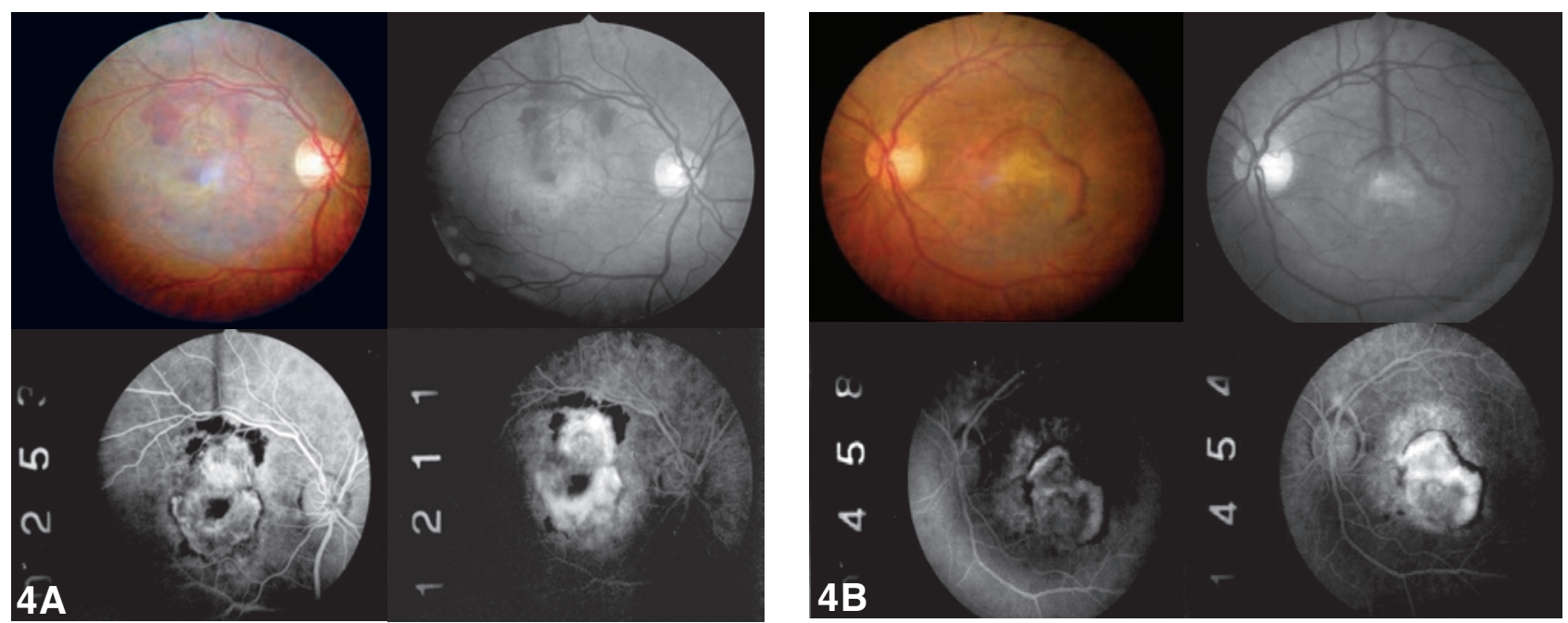

Figura 4: DMRI forma exsudativa subfoveal clássica na mesma paciente: (A) olho direito; (B) olho esquerdo

A DMRI é afecção do idoso, de evolução crônica, que ocorre bilateralmente, causando cegueira legal; a visão periférica é preservada.

A raça branca é a mais atingida e o sexo masculino o mais frequentemente comprometido.

Alguns fatores de risco têm sido incriminados: o fator genético, genes (ABCR, fator $\mathrm{H}$ do complemento) são relatados. Fatores outros, entre eles a idade, obesidade, tabagismo, hipertensão arterial, doenças cardiovasculares também são descritos.

Relacionam-se ainda fatores ambientais, como a exposição crônica à luz azul, carências alimentares e distúrbio no metabolismo dos lipídios (ácidos graxos) $)^{(4)}$.

A DMRI clinicamente apresenta-se sob duas formas distintas: a forma atrófica ou seca e a forma exsudativa, úmida ou vascular (a mais grave).

A sintomatologia inicial, devido ao comprometimento macular, é a diminuição da sensibilidade ao contraste: tem-se a impressão de falta de luz para ler ou escrever, as imagens podem parecer embaçadas ou amareladas; diminuição da acuidade visual; percepção de linhas retas como deformadas ou onduladas; mancha sombreada central e por fim escotoma. Fotopsias também são descritas.

Ao exame oftalmoscópico, na forma atrófica ou seca, são vistas áreas de atrofia das células do epitélio pigmentado da retina, mescladas com áreas de hipertrofia ou hiperplasia destas células. Zonas de cicatriz são formadas e nelas encontradas drusas do tipo duro ou cuticulares (Figura 3).

$\mathrm{Na}$ forma exsudativa ou úmida predominam os neovasos e a exsudação sero-hemorrágica; as drusas quando presentes são do tipo mole ou serosas (Figura 4).

\section{Histopatologia da DMRI atrófica}

Na forma atrófica ou seca é nítida a obliteração parcial ou total dos vasos da córiocapilar na região macular $^{(5)}$. A membrana de Bruch (MB) mostra-se espessada, basofílica, com calcificação da sua porção elástica. Nela podem ocorrer fendas ou roturas. O epitélio pigmentado da retina (EPR) nestes locais apresenta-se atrófico e estão presentes células pigmentadas hipertróficas ou hiperplásicas, são encontrados macrófagos, com pigmento no citoplasma, nas vizinhanças destes locais (Figura 5).

A retina sensorial sofre degeneração microcística e macrocística, esta por sua vez dá origem à retinosquise. O processo degenerativo das estruturas retinianas por vezes é tão profundo, associado à fibrose glial intensa, que possibilita o contato da membrana limitante externa da retina com a lâmina vítrea da membrana de Bruch (Figura 6). Pseudoburacos são vistos na parede interna do macrocisto; o buraco verdadeiro, caracterizado pela perfuração total da espessura retiniana, com suas extremidades arredondas, é excepcional.

\section{Histopatologia da DMRI exsudativa}

Na forma exsudativa ou úmida a histopatologia é caracterizada pela profusão de neovasos e a exsudação sero-hemorrágica. Os neovasos provêm da córiocapilar coroidiana ou mesmo dos vasos retinianos.

De início os neovasos se distribuem por baixo do epitélio pigmentado retiniano (EPR) deslocando-o; esta fase é clinicamente descrita como a forma oculta da neovascuralização somente evidenciável pelo exame 

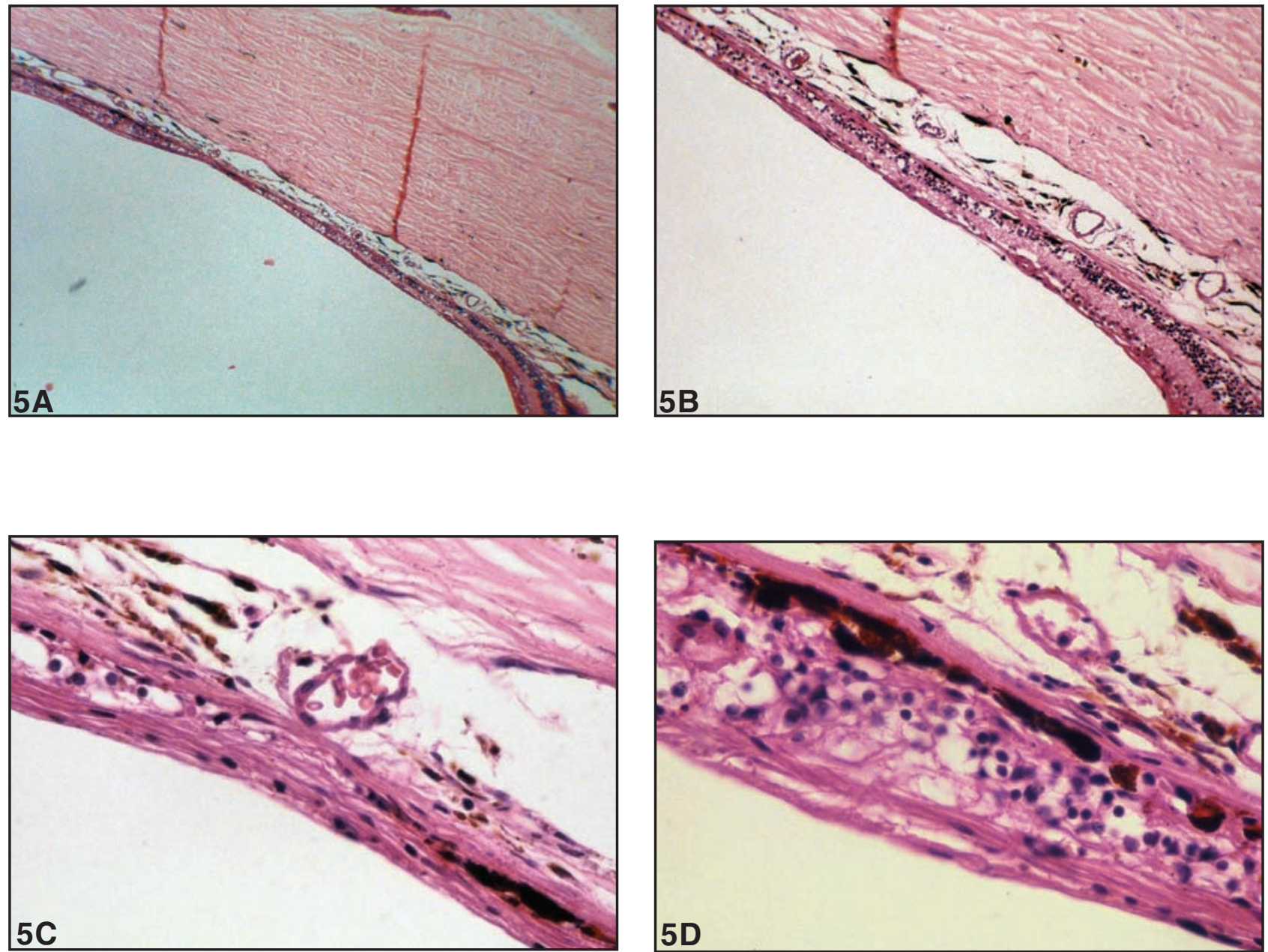

Figura 5: Histopatologia DMRI atrófica: (A) Estruturas da retina substituídas por tecido fibroglial 10x ; (B) 20x; (C) 40x col. HE; (D) Atrofia da córiocapilar (CCC), epitélio pigmentado retina (EPR), retina atrófica e cística 40x col. HE
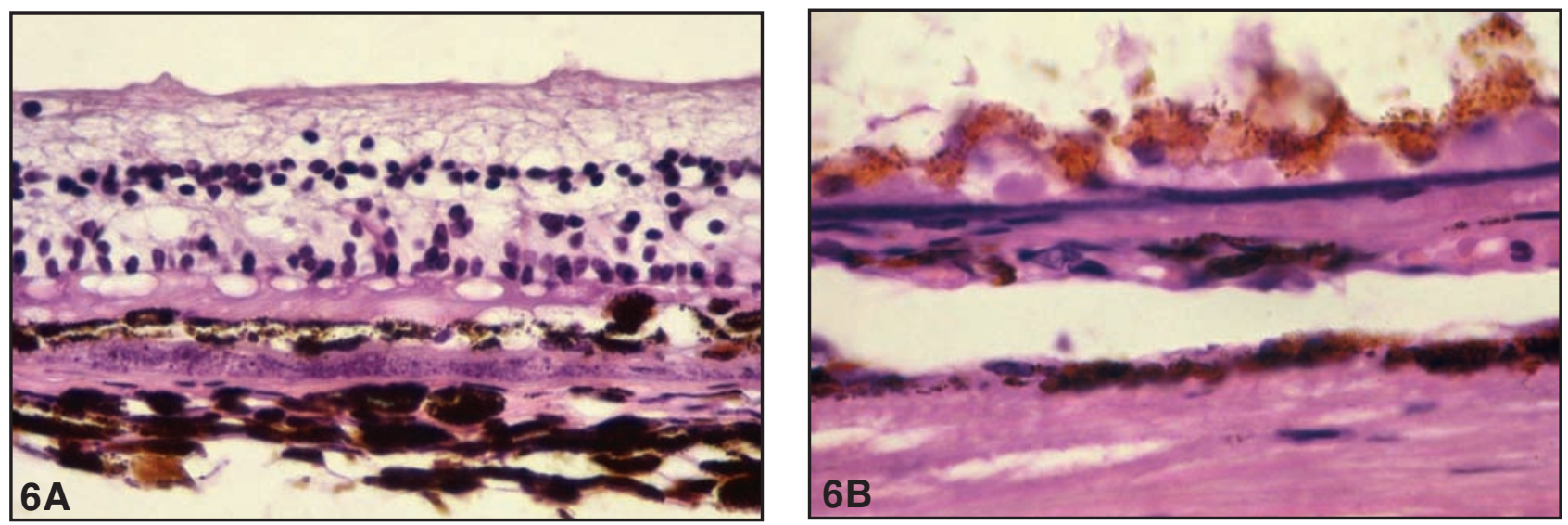

Figura 6: Histopatologia DMRI atrófica: (A) Atrofia epitélio pigmentado (EPR), grânulos basófilos na membrana de Bruch (MB) e obliteração dos vasos da córiocapilar (CCC); (B) Hipertrofia do EPR, basofilia da MB, obliteração parcial da CCC e atrofia da coróide 40x col. HE 


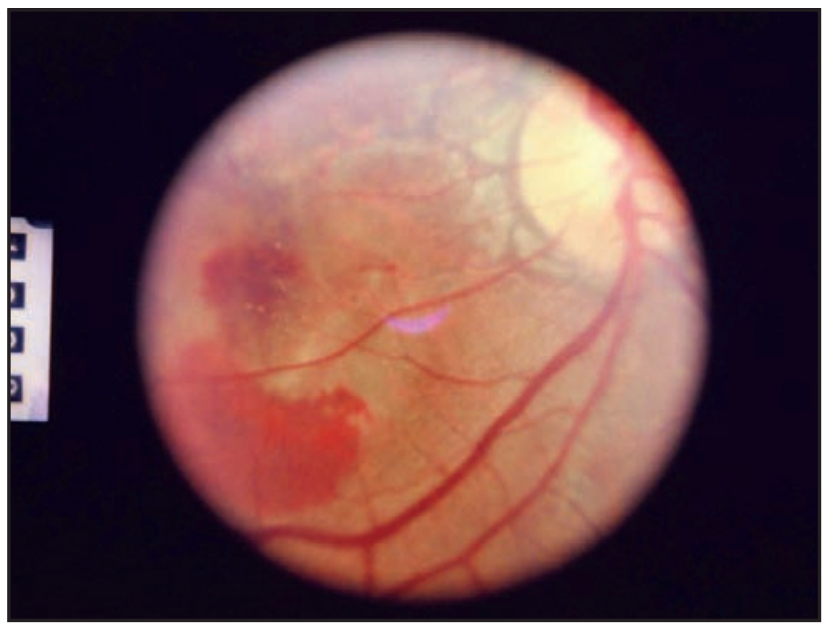

Figura 7: Retinografia simples - DMRI forma exsudativa com estrias angióides

com imagens: angiografia com fluoresceína ou indocianina verde e atualmente com grande auxílio da tomografia de coerência ótica.

Na sua progressão os neovasos, através das roturas na $\mathrm{MB}^{(5,6)}$, penetram no espaço sub-retiniano, progridem em direção à superfície interna da retina e comprometem o corpo vítreo. Este tipo de vascularização é a forma clássica da vascularização, visível à oftalmoscopia simples (Figura 7).

A hemorragia extravasada é invadida por fibroblastos, o colágeno depositado forma um tecido de granulação que é o precursor da densa cicatriz subretiniana, cognominada de degeneração disciforme da mácula, que representa o estádio avançado da doença e nela pode ocorrer metaplasia óssea inclusive (Figura 8).

As drusas são descritas tanto na forma atrófica como na forma exsudativa da DMRI; são apresentadas sob dois aspetos distintos: as drusas duras, presentes na forma atrófica e as drusas moles, na forma exsudativa.

As drusas duras ou cuticulares são elevações ou agregados de matriz extracelular, dispostas na superfície da MB (Figura 9); prováveis produtos sintetizados pelas células do $\mathrm{EPR}^{(7,8)}$; arredondadas, hialinas, eosinófilas, corando-se pelo reagente ácido periódico Schiff (PAS) e se basófilas deve-se ao acúmulo de cálcio. Os lipídios se presentes são evidenciados por corantes osmiofílicos. A apoptose tem papel no desenvolvimento dessas drusas.

À imuno-histoquímica as drusas revelam a presença de apoliproteínas B e E, imunoglobulinas, fibrinogênio, vitronectina.

As drusas moles são depósitos na lâmina basal da $\mathrm{MB}$, à microscopia ótica aparecem como placas extensas em camadas de material granular mole, eosinófilo,
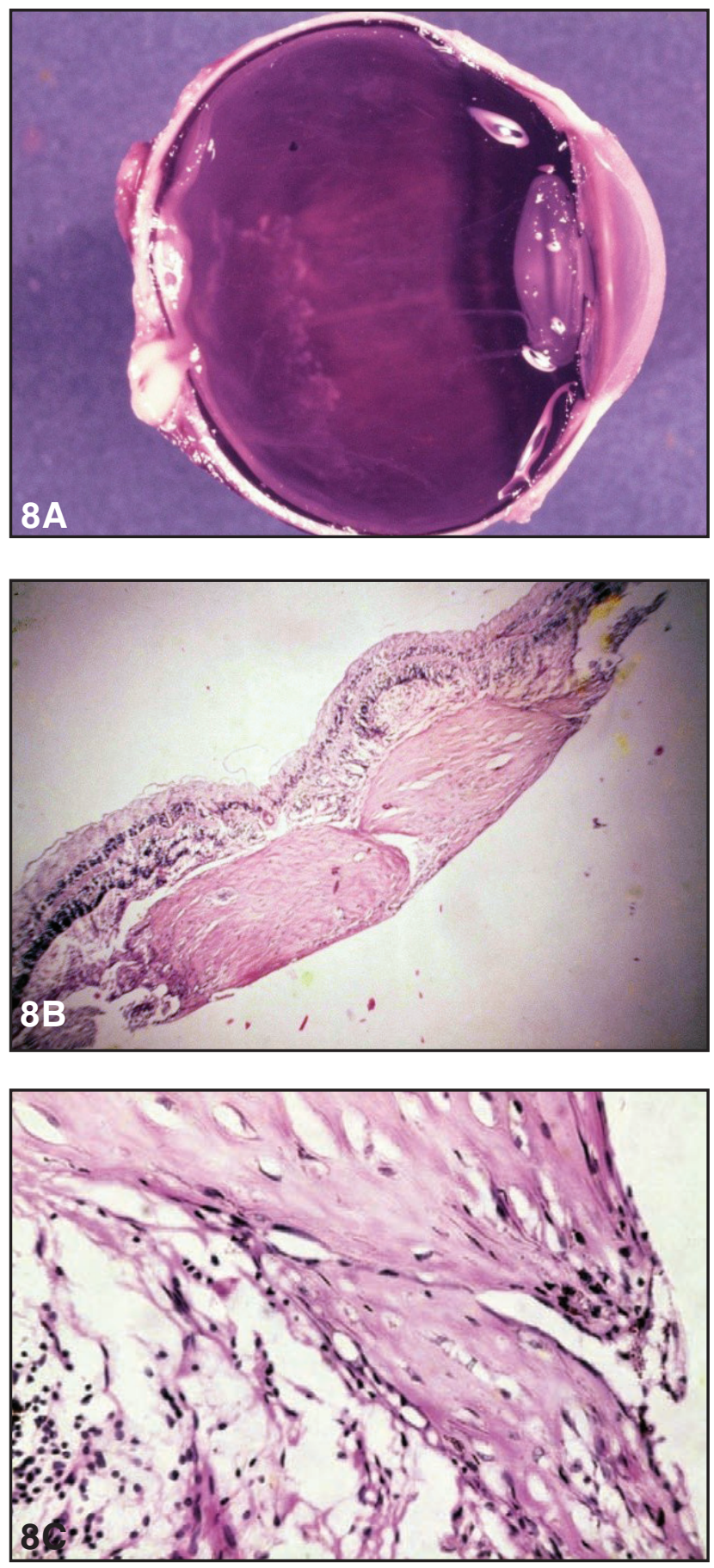

Figura 8: (A) Degeneração disciforme da mácula (macroscopia); (B) Massa tecido fibroso sub-retiniano 20x col. HE; (C) maior aumento 40x col. HE

deslocando o EPR da superfície interna da MB (Figura 10), interferem nas trocas metabólicas da córiocapilar e EPR; as clivagens formadas dão passagem a neovasos e as complicações advindas.

Na etiopatogênese da DMRI, sobretudo na sua forma exsudativa vascular, é importante constatar o po- 


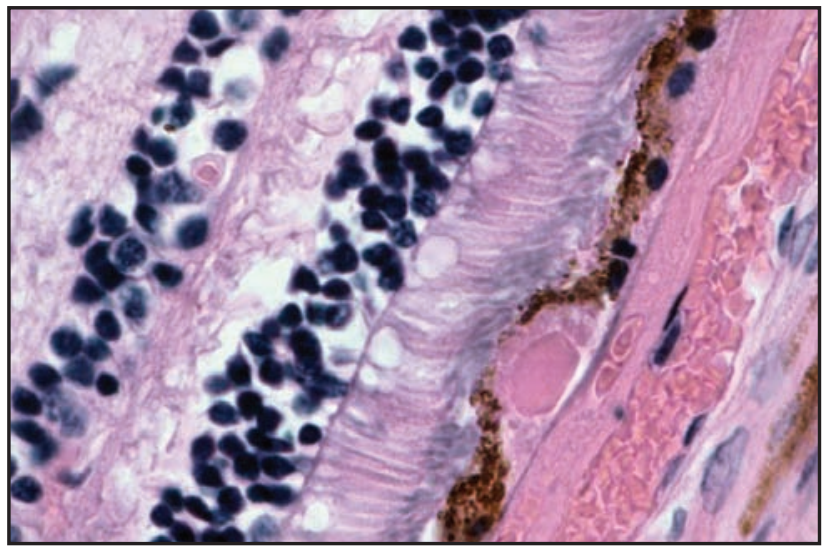

Figura 9: Drusas duras, elevações na superfície da MB 40x col. HE

der angiogênico do fator de crescimento vascular endotelial (VEGF) identificado em membranas removidas cirurgicamente em casos de DMRI. Tal achado motivou a utilização de drogas antiVEGF na prevenção e tratamento desta doença $a^{(9,11)}$.

Os lipídios têm papel fisiopatogênico na DMRI; o acúmulo de lipoproteínas no curso do envelhecimento na MB e a presença de lipídios nas drusas têm contribuição relevante ${ }^{(12,13)}$. Os ácidos graxos poliinsaturados tipo ômega-3 (EPA, DHA) são antioxidantes usados na prevenção da DMRI. O colesterol total para alguns é tido como fator de risco na DMRI no tipo atrófica, entretanto para o tipo exsudativo não é significativo.

Nos debates concernentes à patogênese da DMRI é necessário que consideremos o papel da luz violeta azul e radiação UVA; elas danificam as estruturas da retina, mais especificamente a função das células fotorreceptoras e das células do EPR, comprometendo o DNA mitocondrial e causando morte apoptótica $^{(4)}$.

É necessário ao dissertarmos sobre a DMRI que abordemos a Vasculopatia Coroidal Polipoidal como entidade clínica distinta ${ }^{(14)}$. É caracterizada por dilatação ou ectasia em vaso normal coroidiano, vistos como protusões aneurismáticas, com estrutura tipo pólipo esferoidal, de cor amarelo-avermelhado; a hemorragia macular quando presente lembra o tipo exsudativo da DMRI.

A maculopatia relacionada à idade é bilateral, se associa a drusas serosas, superiores a 125 micra de diâmetro, com alterações do EPR hipo ou hiperpigmentado. Pode evoluir para a forma atrófica da DMRI ou a forma exsudativa, neovascular.

Vale ressaltar o avanço obtido com a utilização da tomografia de coerência ótica espectral cuja alta re-

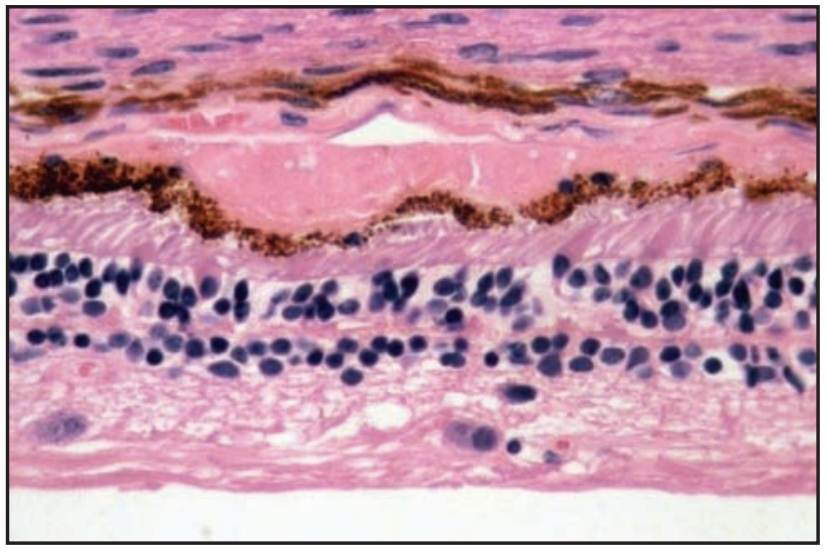

Figura 10: Drusas moles, depósitos na lâmina basal da MB 40x col. HE

solução e sua velocidade aumentada permitem visualizar as camadas retinianas, comparativamente às vistas em preparações histológicas, e consequentemente localizar com precisão a lesão com detalhes em tridimensionalidade ${ }^{(15,16)}$.

\section{Abstract}

Age related macular degeneration (ARMD) is a disease of old people with chronic evolution causing legal blindness. Clinically is classified as: atrophic or dry form and the wet form. Histopathologically the atrophic form is characterized by increased choriocapillaris wall thickness with partial or total lumen obliteration, retinal pigmented epithelium atrophy and hard drusen.In the wet form the most important feature is the neovascular proliferation in the retinal layer, hemorrhage, soft drusen and at ending stage disciform scar in the subretinal space. Angiogenic factors have been admitted in the etiology of $A R M D$ and recently antiangiogenic drugs are used as treatment.

Keywords: Macular degeneration/pathology; Aging/physiology; Visual acuity/physiology

\section{ReferênCIAS}

1. Pournaras CJ. Pathologies vasculaires oculaires. Paris: Elsevier Masson; 2008.

2. Bonfils D .www.dmlainfo.fr: une version plus dynamique [commentaire]. J Fr Ophtalmol. 2009; 32(9).

3. Leveziel N, Delcourt C, Zerbib J, Dollfus H, Kaplan J, Beulian P, Coscas G, Souied EH, Soubraine G. Epidémiologie de la dégénérescence maculaire liée l'âge. J Fr Ophtalmol. 2009; 32(6): 440-51.

4. Dutot M, Rambaux L, Warner M, Rat P. Modulation du stress oxidant par la myrtille riche en polyphenoic sur in modèle de cellules humaines de rétine. J Fr Ophtalmol. 2008; 31(10): 975-80 
5. Hogan MJ, Zimmerman LE. Ophthalmic pathology: an atlas and textbook. 2nd ed. Philadelphia: W.B. Saunders; 1962.

6. Eagle RC. Eye pathology: an atlas and basic text. Philadelphia: W.B.Saunders; 1999.

7. Spencer WH, editor. Ophthalmic pathology: an atlas and textbook . 4th ed. Vol. 2. Vitreous-retina. Philadelphia: W.B.Saunders; 1996.

8. Soubrane G, Coscas G, Souied E. Les DMLAs. Paris: Elsevier Masson; 2007.

9. Bhutto IA, Uno K, Merges C, Zhang L, McLeod DS, Lutty GA. Reduction of endogenous angiogenesis inhibitors in Bruch's membrane of the submacular region in eye with age related degeneration. Arch Ophthalmol. 2008; 126 (5): 670-78.

10. Tatar O, Shinoda K, Kaiserling E, Pertile G, Eckardt C, Mohr A, et al. Early effects of triamcinolone on vascular endothelial growth factor and endostatin in human choroidal neovascularization. Arch Ophthalmolol. 2008; 126(2): 193-9.

11. Michell P, Korobelnik JF, Lauzetta P, Hotz FG, Prünte C, Schmidt Er S. Ranibizumab (Lucentis) in neovascular agerelated macular degenerative clinical trials. Br J Ophthalmol. 2010; 94(1):2-13.

12. Torres RJA, Maia M, Noronha L, Farah ME, Luchini A, Brick $\mathrm{D}$ et al. Avaliação das alterações precoces na coróide e esclera ocorridas em coelhos hipercolesterolêmicos. Estudo histológico e histomorfométrico. Arq Bras Oftalmol. 2009; 72(1): 68-74.
13. Torres RJA, Maia M, Muccioli C, Winter G, Souza GK, Pasqualotto LR, et al. Fatores modificáveis da degeneração macular relacionada à idade. Arq Bras Oftalmol. 2009; 72(3): 406-12.

14. Ciardella AP, Donsoff IM, Huang SJ, Costa DL, Yannuzzi LA. Polypoidal choroidal vasculopathy. Surv Ophthalmol. 2004; 49(9): 25-37.

15. Ferrara DC, Calucci D, Oréfice JL, Costa RA. Avaliação ocular multimodal em doenças heredodistróficas e degenerativas da retina. Rev Bras Oftalmol. 2009; 68(5): 309-17

16. Coscas G, Coscas F, Vismara S, Soueid E, Soubraine G. Tomographie par cohérence optique de type Spectral Domain dans la dégénérescence maculaire liée à l’âge. J Fr Ophtalmol. 2008;31(4): 353-61.
Endereço para correspondência: Joaquim Marinho de Queiroz
Tv. Mauriti, 3157 - Marco
CEP: 66.095-360 - Belém (PA), Brasil jomaquei@amazon.com.br 